\title{
Regional and state heterogeneity of monetary shocks in Argentina
}

\author{
Emilio Blanco ${ }^{\mathrm{a}}$, Pedro Elosegui ${ }^{\mathrm{a}, \mathrm{d}, \mathrm{e},{ }^{*}}$, Alejandro Izaguirre ${ }^{\mathrm{b}}$, Gabriel Montes-Rojas ${ }^{\mathrm{c}}$ \\ ${ }^{\text {a } B a n c o ~ C e n t r a l ~ d e ~ l a ~ R e p u ́ b l i c a, ~ A r g e n t i n a ~}$ \\ ${ }^{\mathrm{b}}$ Universidad de San Andrés, Buenos Aires, Argentina \\ ${ }^{\mathrm{c}}$ Instituto Interdisciplinario de Economía Politica de Buenos Aires (IIEP-BAIRES-UBA) and CONICET, Facultad de Ciencias Económicas, Universidad \\ de Buenos Aires, Córdoba 2122, 2do piso, C1120AAQ, Ciudad Autónoma de, Buenos Aires, Argentina \\ ${ }^{\mathrm{d}}$ LiD Maimonides, Universidad Nacional de La Plata, Buenos Aires, Argentina \\ ${ }^{\mathrm{e}}$ University of Illinois at Urbana, Champaign, USA
}

\section{A R T I C L E I N F O}

\section{JEL classification:}

E52

G21

R11

R12

Keywords:

Monetary policy

Monetary transmission

Regional effects

\begin{abstract}
A B S T R A C T
This paper empirically investigates how economic activity in Argentina at regional and provincial (i.e., state) levels responds to central national monetary policy shocks, as given by a change in the interest rate. Regional heterogeneity of monetary shocks exists in Argentina. At the regional level the long-term effects of increasing the interest rate are negative and statistically significant. At the provincial level, 11 provinces show a negative and significant impact of a shock on the interest rate over employment. However, there are 13 provinces in which the effect is not statistically significant, including the City of Buenos Aires and Buenos Aires Province. Bayesian methods are implemented to study the discrepancies in the impact on different provinces.
\end{abstract}

\section{Introduction}

As noted by Carlino and DeFina (1999) the idea that policy changes affect states differently is intuitive given the heterogeneity of state economies and their financial and trade networks. State heterogeneity in a state's response to U.S. Federal Reserve Board actions can be deduced from traditional and new credit-based theories (Bernanke \& Blinder, 1988; Kashyap and Stein, 1994; Kashyap, Stein, and Wilcox, 1993) of the monetary policy transmission mechanism. Park and Hewings (2012) found that industry mix and even more critically the place in the value chain production contributed to the asymmetries. In the business literature, the notion of a whipsaw effect has been introduced to show how economies with production systems at the early stages of a value chain experience greater fluctuations that those whose production is close to final goods. Further, the latter economies' business cycles will be more highly correlated with the national ones than the former economies.

As a result, it is important to account for feedback effects among regions when modeling regional responses to aggregate shocks, and policymakers actions should take into account potential extreme or unexpected effects in some regions. The simple estimation of a standard vector autoregressive (VAR) for each region, as is being done in empirical macroeconomic and monetary studies may result in serious misspecification since indirect effects of policy actions (operating, for instance, through trade and financial linkages among regions) are neglected. See the literature review in Dominguez-Torres and Hierro (2019) for a recent discussion of different models implemented in this context, and empirical evidence for the U.S., Europe and few other countries.

This paper is the first to empirically investigate how economic activity in Argentina at regional and provincial (i.e., state) levels

\footnotetext{
* Corresponding author. Banco Central de la República, Argentina.

E-mail addresses: emilio.blanco@bcra.gob.ar (E. Blanco), elo@illinois.edu (P. Elosegui), izaguirre.ale@gmail.com (A. Izaguirre), gabriel.montes@ fce.edu.ar (G. Montes-Rojas).
} 
responds to central or national monetary policy shocks. To do this we implement different spatial macro-type structural vector autoregressive (SVAR) models where we study how a change in the interest rate (i.e., monetary policy shock) affect employment in regions or provinces within Argentina, taking into account the spatial correlations among them. We thus evaluate the short-, mediumand long-term effects of monetary shocks on Argentine regions by computing the impulse response functions.

We find that regional heterogeneity exists in Argentina, resulting in differential effects of monetary policy shocks. At the regional level it is interesting to note that the North-East (NEA) region is the only one that does not show a significant impact of the shock on the interest rate on employment. In all other cases, the results are statistically significant, showing that a tightening of the monetary policy results in a negative effect on employment. Ciudad Autónoma de Buenos Aires (CABA) and Great Buenos Aires (GBA) together with the Centro region show a similar behavior to that of the national aggregate. Meanwhile, the Sur, North-West (NOA) and Cuyo regions show the largest negative effect on regional employment. At the provincial level, 11 provinces show a negative and significant impact of the shock on the interest rate over employment, accumulated to 10 periods. However, there are 13 provinces in which the effect is not statistically significant. Among the latter, the two main jurisdictions (GBA-CABA and Buenos Aires) are noteworthy due to their nonsignificant impact, together with other relatively less developed provinces, such as Formosa and Patagonian provinces. On the other hand, the provinces that show significant impacts have diverse ranges of economic and financial development. The preliminary empirical analysis of the discrepancies in the impact of the monetary shock on the different states is made in the last section applying Bayesian methods.

This paper is organized as follows. Section 2 develops the econometric model used to estimate and evaluate the shocks. Section 3 describes the Argentinean data and section 4 presents the econometric results for Argentina. Section 5 uses the results from the previous section to evaluate potential causes of the asymmetric responses using Bayesian techniques. Section 6 concludes and proposes further lines of research.

\section{Econometric model}

\subsection{Maximum likelihood model}

As mentioned in the Introduction, the aim of this work is to account for the spatial heterogeneity of macroeconomic shocks.

In Carlino and DeFina's $(1998,1999)$ approach interdependence across states is dealt with by allowing the lagged output of other regions to enter the equations of each specific region or state. However, no contemporaneous feedback is allowed (i.e., simultaneous propagation of economic disturbances among regions is excluded). This assumption is reflected in the identification scheme that is adopted, which rules out any contemporaneous interdependence among states by means of a set of overidentifying restrictions imposed on the contemporaneous VAR coefficients matrix. As a result, spatial propagation of monetary policy shocks is assumed to take place at least with a one-period time lag. De Lucio and Izquierdo (1999) contribution, while ruling out lagged feedback effects among regions, does allow for contemporaneous correlation among the VAR model residuals. Their preferred specification consists of a set of regional macro-type SVARs, jointly estimated using seemingly unrelated regression (SUR) techniques.

Di Giacinto (2003) uses geographical proximity in the model specification assuming that information with respect to the nearest neighboring areas is relevant in predicting the process at a given location. He follows the standard approach in spatial econometrics (see, e.g., Anselin, 1988, chap. 3; Martin and Oeppen, 1975; Pfeifer and Deutsch, 1980; Pfeifer and Bodily, 1990) where a priori information on the spatial connectivity structure underlying the observed data is made operational within the VAR model through a sequence of spatial weights matrices, defined according to a proper spatial weighting scheme. Through the sequence of spatial weights matrices, a set of parameter restrictions is imposed on the VAR coefficients matrices. On one hand, these restrictions allow for the identification and estimation of a single monetary policy shock series for all regions by eliminating the degrees-of-freedom constraint incurred by VAR models as the cross-sectional dimension of the model increases. On the other hand, spatial constraints are useful in modeling contemporaneous interdependence among regions while preserving a sufficiently large number of restrictions for structural parameter identification.

Bertanha and Haddad (2008) apply Di Giacinto's model to Brazilian states and analyze the presence of regional asymmetries in the impact of monetary shocks for the 27 states of Brazil. The authors use a SVAR model with spatial weighted matrices. In fact, they can test the difference between the contiguity matrix and a trade-weighted matrix, as well as the importance of lagged and direct spatial effects. The direct effects predominate in the results, while the trade matrix enhances the impact of the shock in the state of São Paolo and Manaus (tax-free zone) where trade is a highly relevant sector. This is in fact the closest paper to our analysis.

We follow the model proposed in Di Giacinto (2003) that constructs a structural VAR (SVAR) model with temporal as well as spatial lags. The spatial SVAR model adds spatial information in the model making use of techniques commonly employed in spatial econometrics. Broadly speaking, the idea of spatial heterogeneity is given by the fact that the output of any spatial unit could be directly or indirectly affected by the output of any of the other units. Such idea can be covered by the traditional SVAR as in Carlino and DeFina (1998, 1999), Fraser et al. (2014) and Guo and Tajul (2017). The innovation of the spatial SVAR model is the introduction of the contiguity matrix in the context of SVAR.

The model considers three sets of variables. The first set, denoted as $\mathbf{x}_{t}=\left[x_{1 t}, x_{2 t}, \ldots, x_{K t}\right]^{\prime}$, represents $K$ macroeconomic aggregate control variables. Under our specification, such variables are given by consumer's price index (CPI), the U.S. dollar/peso exchange rate and gross domestic product (GDP), i.e., $K=3$. These variables correspond to the aggregate or national level. The second set of variables, denoted by $\mathbf{y}_{t}=\left[y_{1 t}, y_{1 t}, \ldots, y_{N t}\right]^{\prime}$, includes the stacked values of the output variable measured on the $N$ spatial units. Our spatial variable is total formal employment in each regional/state unit. As discussed below this is the only variable for which we have spatial as well as temporal heterogeneity in Argentina. The third set is given by a single variable, the monetary policy instrument, the interest rate in our 
model, denoted by $r_{t}$. Following the macroeconomics literature, our interest is to estimate the effect of a shock in this variable on the output variables, which is measured by employment.

Setting $\mathbf{z}_{t}=\left[\mathbf{x}_{t}^{\prime}, \mathbf{y}_{t}^{\prime}, r_{t}\right]^{\prime}$, the spatial SVAR model has the following expression

$$
\mathbf{C}_{0} \mathbf{z}_{t}=\mathbf{C}_{1} \mathbf{z}_{t-1}+\ldots+\mathbf{C}_{p} \mathbf{z}_{t-p}+\mathbf{u}_{t}
$$

where $\quad \mathbf{u}_{t}=\left[u_{1 t}^{x}, \ldots, u_{K t}^{x}, u_{1 t}^{y}, \ldots, u_{N t}^{y}, u_{t}^{r}\right] \quad$ is $\quad$ an orthogonal multivariate white-noise series, i.e., $E\left(\mathbf{u}_{t}\right)=\quad 0$, $E\left(\mathbf{u}_{t} \mathbf{u}_{t-h}^{\prime}\right)=\Omega=\operatorname{diag}\left(\left[\sigma_{x 1}^{2}, \ldots, \sigma_{x K}^{2}, \sigma_{y 1}^{2}, \ldots, \sigma_{y N}^{2}, \sigma_{r}^{2}\right]^{\prime}\right)$ if $h=0$ and $E\left(\mathbf{u}_{t} \mathbf{u}_{t-h}^{\prime}\right)=0$ elsewhere for $h \geq 0$.

The $\mathbf{C}_{0}$ matrix has the following block triangular structure

$$
\mathbf{C}_{0}=\left[\begin{array}{ccc}
\mathbf{I}_{K} & 0 & 0 \\
0 & \mathbf{C}_{0}^{y y} & 0 \\
-\mathbf{C}_{0}^{x x} & -\mathbf{C}_{0}^{r y} & 1
\end{array}\right],
$$

where $\mathbf{C}_{0}^{r x}$ is a $(1 \times K)$ vector of unrestricted coefficients relating the policy instrument to the contemporaneous values of the macro variables $\mathbf{x}$, and where

$$
\mathbf{C}_{0}^{r y}=a_{0}^{r y} \omega^{\prime}
$$

$a_{0}^{r y}$ is a scalar parameter to be estimated and $\omega$ is a vector of $N$ fixed coefficients representing the average weight of employment of each spatial unit with respect to the national aggregate. This determines that the interest rate is affected by employment only through a national weighted average. This restriction is motivated by the assumption that only aggregate output enters the Central Bank information set and, hence, the monetary instrument response function. The $\mathbf{C}_{0}^{y y}$ matrix models simultaneous spatial interdependence by the following structure

$$
\mathbf{C}_{0}^{y y}=\mathbf{I}_{N}-\phi_{0} W
$$

where $\phi_{0}=\operatorname{diag}\left(\left[\phi_{0}^{1}, \phi_{0}^{2}, \ldots, \phi_{0}^{N}\right]^{\prime}\right)$ and $W$ is the $N \times N$ spatial weights matrix with typical element $w(i, j)>0$ if locations $i$ and $j$ are contiguous (in a broad sense) and $w(i, j)=0$ elsewhere and if $i=j$.

Two types of restriction are imposed on the $\mathbf{C}_{h}$ matrices $(h=1, \ldots, p)$. First,

$$
\mathbf{C}_{h}=\left[\begin{array}{ccc}
\mathbf{C}_{h}^{x x} & \mathbf{C}_{h}^{x y} & \mathbf{C}_{h}^{x r} \\
\mathbf{C}_{h}^{y x} & \mathbf{C}_{h}^{y y} & \mathbf{C}_{h}^{y r} \\
\mathbf{C}_{h}^{r x} & \mathbf{C}_{h}^{r y} & \mathbf{C}_{h}^{r r}
\end{array}\right]
$$

Second, spatial restrictions are imposed on blocks $\mathbf{C}_{h}^{y y}$ that have structure

$$
\mathbf{C}_{h}^{y y}=\sum_{k=1} \phi_{h} W
$$

where $\phi_{h}=\operatorname{diag}\left(\left[\phi_{h}^{1}, \phi_{h}^{2}, \ldots, \phi_{h}^{N}\right]^{\prime}\right)$. Coefficients $\mathbf{C}_{h}^{x y}$ and $\mathbf{C}_{h}^{r y}$ relating the macro variables and the monetary instrument to past values of the spatial output series are constrained as follows

$$
\begin{aligned}
& \mathbf{C}_{h}^{x y}=\mathbf{a}_{h}^{x y} \omega^{\prime} \\
& \mathbf{C}_{h}^{r y}=\mathbf{a}_{h}^{r y} \omega^{\prime}
\end{aligned}
$$

where $\mathbf{a}_{h}^{x y}$ and $\mathbf{a}_{h}^{r y}$ are, respectively, a $k$-dimensional vector and a scalar to be estimated. All remaining blocks are left unrestricted, as in the standard VAR specification. Di Giacinto (2003) derives consistent estimators of model parameters applying Full Information Maximum Likelihood method. Further details on the estimation procedure can be found in that paper.

Shock identification is embedded in the structural model described above. As noted by Dominguez-Torres and Hierro (2019) this is the most common structure for identification of monetary shocks in spatial models, where the policy instrument (i.e., $r_{t}$ ) is regressed on all other contemporaneous variables and temporal lags. Their meta-analysis suggests, however, "that the choice of the identification scheme appears to have no effect on the pattern of the responses yielded by these studies, since such responses broadly exhibit a hump-shaped trajectory (when a contractive shock is analyzed) irrespective of the identification scheme implemented." (p.4) Our preliminary evidence also confirm that the results are robust to different identification procedures.

\subsection{Models}

We estimate three different models. One the one hand we estimate a SVAR model that ignores spatial heterogeneity, and use this 
models as a benchmark. This corresponds to a national-level model, a standard empirical macroeconomics SVAR in the line of Christiano et al. (1996). ${ }^{1}$

On the other hand, based on the general setting presented above, we estimate two spatial models, the State Model (SM) and the Regional Model (RM). The main difference between them is given by the level of spatial aggregation. The SM considers $N=24$ spatial units given by the 23 states plus a conglomerate formed by the City of Buenos Aires and its contiguous neighborhood (known as Gran Buenos Aires, CABA-GBA), while the RM considers $N=6$ spatial units given by 5 regions (groups of states) plus the previously defined conglomerate. See section 3 for a description of the Argentine regional structure.

Regarding the spatial structure of the models, for the SM we used a Queen type contiguity matrix, that is, two states are considered neighbors if they have a common border. ${ }^{2}$ For the RM, however, we used a distance based contiguity matrix with the following structure. Let $W\left[w_{i j}\right]$ be the contiguity matrix,

$$
w_{i j}=\frac{d(i, j)^{-1}}{\sum_{j=1}^{N} d(i, j)^{-1}} .
$$

The strength of the relation between two spatial units, $w_{i j}$, is given by the inverse of the distance, as measured by centroids, among regions, $d(i, j)^{-1}$, considering the inverse of the distance to all the regions, $\sum_{j=1}^{N} d(i, j)^{-1}$. This configuration gives more weight to closer units. Unlike the Queen matrix, under this configuration all regions are considered neighbors. Both contiguity matrix are rownormalized.

For both models the spatial lag order was set to 1 , and the temporal lags were set to $p=2$, thus the matrix (5) has the following elements:

- $\mathbf{C}_{h}^{x x}$ is a $(3 \times 3)$ matrix relating the macro variables to their own values $h$ periods ago;

- $\mathbf{C}_{h}^{x r}$ is a $(3 \times 1)$ matrix relating the macro variables to the interest rate $h=1,2$, periods ago;

- $\mathrm{C}_{h}^{y x}$ is a $(N \times 3)$ matrix relating the total employment in each spatial unit to the macro variables $h=1,2$, periods ago;

- $\mathbf{C}_{h}^{y r}$ is a $(N \times 1)$ matrix relating the total employment in each spatial unit to the interest rate $h=1,2$, periods ago;

- $\mathbf{C}_{h}^{r x}$ is a $(1 \times 3)$ matrix relating the interest rate to the macro variables $h=1,2$, periods ago;

- $\mathbf{C}_{h}^{r r}$ is a $(1 \times 1)$ matrix relating the interest rate to his own value $h=1,2$, periods ago.

Regarding the elements $\mathbf{C}_{h}^{x y}$ and $\mathbf{C}_{h}^{r y}$, they relate the macro variables and the interest rate to a weighting average of the total employment $h=1,2$, periods ago, respectively.

Following equations (7) and (8) we have that

- $\mathbf{a}_{h}^{x y}$ is a $(3 \times 1)$ matrix relating the macro variables to a weighting average of the total employment $h=1,2$, periods ago.

- $\mathbf{a}_{h}^{r y}$ is a $(1 \times 1)$ matrix relating the interest rate to a weighting average of the total employment $h=1,2$, periods ago.

We follow Bertanha and Haddad (2008) for defining the weights vector $\omega$,

$$
\omega^{\prime}=\left(\omega_{1}, \omega_{2}, \ldots, \omega_{N}\right)
$$

with $\omega_{j}=\frac{\sum_{t=1}^{T}\left(\operatorname{TotEmp}_{\mathrm{j} t} / \mathrm{NatEmp}_{t}\right)}{T}$, where TotEmp $p_{j t}$ is the total employment in spatial unit 1 at time $t$ and $\operatorname{NatEmp}_{t}=\sum_{n=1}^{N}\left(\mathrm{TotEmp}_{n t}\right)$ is the

\footnotetext{
${ }^{1}$ This model considers the macro variables, the interest rate and the aggregate employment $\left(y_{t}\right)$, that is, it considers the same variables as the spatial models but employment is aggregated at the national level. We maintain the structural form of the non-spatial model as similar as possible to the spatial ones. In particular we consider a model of the form
}

$$
\mathbf{B}_{0} \mathbf{z}_{\mathbf{t}}=\mathbf{B}_{1} \mathbf{z}_{\mathbf{t}-\mathbf{1}}+\ldots+\% \mathbf{B}_{p} \mathbf{z}_{\mathbf{t}-\mathbf{p}}+\mathbf{u}_{\mathbf{t}}
$$

where $\mathbf{z}_{t}=\left[x_{t^{\prime}}, e_{t}, r_{t}\right]$ and $\mathbf{u}_{t}=\left[u_{1 t}^{x}, \ldots, u_{K t}^{x}, u_{t}^{y}, u_{t}^{r}\right]$ is an orthogonal multivariate white-noise series. The $\mathbf{B}_{0}$ matrix has the following block triangular structure

$$
\mathbf{B}_{0}=\left[\begin{array}{ccc}
\mathbf{I}_{K} & \mathbf{0} & \mathbf{0} \\
\mathbf{0} & 1 & \mathbf{0} \\
-\mathbf{B}_{0}^{r x} & -\mathbf{B}_{0}^{r y} & 1
\end{array}\right],
$$

where $\mathbf{B}_{0}^{r x}$ is a $(1 \times K)$ vector of unrestricted coefficients relating the policy instrument to the contemporaneous values of the macro variables $x$, and $\mathbf{B}_{0}^{r y}$ is a coefficient relating the policy instrument to the contemporaneous values of the aggregate employment. As in spatial models, the temporal lags were set to $p=2$.

${ }^{2}$ Stakhovych and Bijmolt (2008, p.408) find that spatial models estimated using the first-order contiguity weights matrix perform better on average than those using the nearest neighbors or inverse distance weights matrices in terms of their higher probabilities of detecting the true model and they have lower MSE of the parameters. 


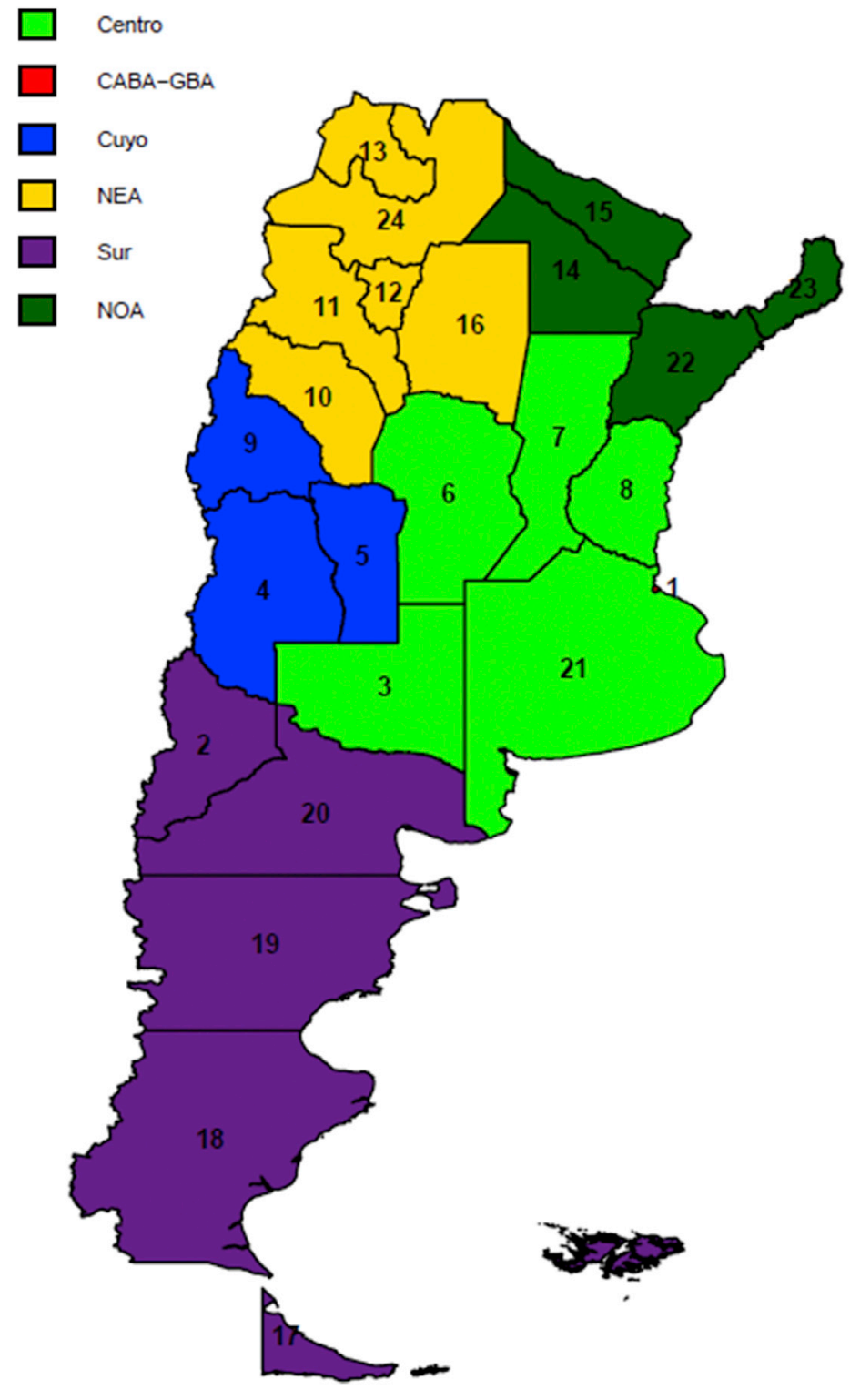

\author{
1 CABA \\ 2 Neuquén \\ 3 La Pampa \\ 4 Mendoza \\ 5 San Luis \\ 6 Córdoba \\ 7 Santa Fe \\ 8 Entre Rios \\ 9 San Juan \\ 10 La Rioja \\ 11 Catamarca \\ 12 Tucumán \\ 13 Jujuy \\ 14 Chaco \\ 15 Formosa \\ 16 Stgo del Estero \\ 17 T. del Fuego \\ 18 Santa Cruz \\ 19 Chubut \\ 20 Rio Negro \\ 21 Buenos Aires \\ 22 Corrientes \\ 23 Misiones \\ 24 Salta
}

Fig. 1. Regions of Argentina.

total employment at national level at time $t$. The weight of each spatial unit is thus given by its relative importance in terms of national employment along the analyzed period.

\subsection{Impulse response functions}

From the model estimates our main interest lies in constructing the impulse response functions (IRFs) from a unit shock (i.e., $1 \%$ increase in the interest rate) in $u_{t}^{r}$ on the $y_{t}$ regional variables. That is, in evaluating the effect at provincial/regional level of an aggregate monetary shock corresponding to a tightening of the monetary policy via an increase of the reference interest rate. We study the effect of this shock on the difference in logarithm of employment, and thus the effects are evaluated on employment growth. The shock is determined by the identification strategy given by the structural model.

Given the complex nature of the maximum likelihood model presented above and the fact that we are not necessarily confident in the Gaussian nature of the shocks, we compute bootstrap standard errors of all parameter estimates. In particular, we consider nonparametric bootstrap samples, with replacement, of quarters with the corresponding structure of lags (using 2 lags), maintaining the geographic structure intact throughout the analysis. IRFs analysis is evaluated using $20 \%$ confidence intervals where we generate a ranking order from the bootstrap samples for each of the 12 periods-ahead used in the IRFs. 
Table 1

Selected economic and financial variables by provinces and regions.

\begin{tabular}{|c|c|c|c|c|c|c|c|c|c|c|c|c|c|}
\hline \multirow[t]{2}{*}{ Province } & \multirow[t]{2}{*}{ Region } & \multirow[t]{2}{*}{ GDP share } & \multicolumn{2}{|c|}{ Employment by sector share } & \multirow[t]{2}{*}{ Public emp. pc } & \multicolumn{3}{|c|}{ Financial shares } & \multirow[t]{2}{*}{ Branch per $10 \mathrm{~K}$} & \multicolumn{2}{|c|}{ Firms by size shares } & \multirow[t]{2}{*}{ Public Bank } & \multirow[t]{2}{*}{ Exports pc } \\
\hline & & & Industry & Services & & Loans & Deposits & Branches & & Small & Large & & \\
\hline GBA-CABA & GBA-CABA & $39.7 \%$ & $20 \%$ & $57 \%$ & $1 \%$ & $54 \%$ & $54 \%$ & $18 \%$ & 0.6789 & $89 \%$ & $4 \%$ & 1 & 0.00018 \\
\hline Buenos Aires & Centro & $13.9 \%$ & $21 \%$ & $42 \%$ & $9 \%$ & $12 \%$ & $12 \%$ & $31 \%$ & 2.2905 & $92 \%$ & $4 \%$ & 1 & 0.00340 \\
\hline Cordoba & Centro & $7.8 \%$ & $21 \%$ & $45 \%$ & $4 \%$ & $7 \%$ & $6 \%$ & $10 \%$ & 1.3811 & $91 \%$ & $4 \%$ & 1 & 0.00286 \\
\hline Entre Rios & Centro & $2.4 \%$ & $19 \%$ & $37 \%$ & $7 \%$ & $2 \%$ & $2 \%$ & $3 \%$ & 1.1489 & $89 \%$ & $5 \%$ & 0 & 0.00117 \\
\hline La Pampa & Centro & $0.9 \%$ & $12 \%$ & $36 \%$ & $8 \%$ & $1 \%$ & $1 \%$ & $2 \%$ & 3.4175 & $88 \%$ & $7 \%$ & 1 & 0.00118 \\
\hline Santa Fe & Centro & $8.8 \%$ & $25 \%$ & $42 \%$ & $5 \%$ & $8 \%$ & $6 \%$ & $10 \%$ & 1.4838 & $90 \%$ & $4 \%$ & 1 & 0.00469 \\
\hline Mendoza & Cuyo & $3.9 \%$ & $19 \%$ & $41 \%$ & $8 \%$ & $2 \%$ & $2 \%$ & $4 \%$ & 0.9374 & $88 \%$ & $6 \%$ & 0 & 0.00082 \\
\hline San Juan & Cuyo & $1.1 \%$ & $17 \%$ & $36 \%$ & $8 \%$ & $1 \%$ & $1 \%$ & $1 \%$ & 0.5726 & $84 \%$ & $9 \%$ & 0 & 0.00230 \\
\hline San Luis & Cuyo & $1.1 \%$ & $31 \%$ & $36 \%$ & $7 \%$ & $0 \%$ & $2 \%$ & $1 \%$ & 1.2260 & $82 \%$ & $11 \%$ & 0 & 0.00141 \\
\hline Chaco & NEA & $1.3 \%$ & $11 \%$ & $40 \%$ & $8 \%$ & $1 \%$ & $1 \%$ & $1 \%$ & 0.6160 & $85 \%$ & $8 \%$ & 1 & 0.00031 \\
\hline Corrientes & NEA & $1.2 \%$ & $15 \%$ & $34 \%$ & $6 \%$ & $1 \%$ & $1 \%$ & $2 \%$ & 0.9571 & $85 \%$ & $8 \%$ & 1 & 0.00022 \\
\hline Formosa & NEA & $0.5 \%$ & $7 \%$ & $32 \%$ & $9 \%$ & $0 \%$ & $1 \%$ & $1 \%$ & 0.4716 & $83 \%$ & $11 \%$ & 0 & 0.00006 \\
\hline Misiones & NEA & $1.3 \%$ & $19 \%$ & $37 \%$ & $6 \%$ & $1 \%$ & $1 \%$ & $1 \%$ & 0.5901 & $85 \%$ & $8 \%$ & 0 & 0.00039 \\
\hline Catamarca & NOA & $0.9 \%$ & $21 \%$ & $35 \%$ & $16 \%$ & $0 \%$ & $0 \%$ & $1 \%$ & 0.6797 & $82 \%$ & $12 \%$ & 0 & 0.00240 \\
\hline Jujuy & NOA & $0.8 \%$ & $21 \%$ & $34 \%$ & $13 \%$ & $1 \%$ & $1 \%$ & $1 \%$ & 0.4901 & $84 \%$ & $10 \%$ & 0 & 0.00062 \\
\hline La Rioja & NOA & $0.6 \%$ & $31 \%$ & $25 \%$ & $15 \%$ & $0 \%$ & $0 \%$ & $1 \%$ & 0.8692 & $80 \%$ & $13 \%$ & 1 & 0.00076 \\
\hline Salta & NOA & $1.7 \%$ & $13 \%$ & $39 \%$ & $8 \%$ & $2 \%$ & $1 \%$ & $1 \%$ & 0.5682 & $85 \%$ & $8 \%$ & 0 & 0.00081 \\
\hline Santiago del Estero & NOA & $1.2 \%$ & $11 \%$ & $41 \%$ & $7 \%$ & $1 \%$ & $1 \%$ & $1 \%$ & 0.6178 & $84 \%$ & $9 \%$ & 0 & 0.00081 \\
\hline Tucuman & NOA & $1.7 \%$ & $15 \%$ & $41 \%$ & $8 \%$ & $2 \%$ & $1 \%$ & $1 \%$ & 0.1933 & $85 \%$ & $8 \%$ & 0 & 0.00062 \\
\hline Chubut & Sur & $2.2 \%$ & $11 \%$ & $33 \%$ & $8 \%$ & $1 \%$ & $1 \%$ & $2 \%$ & 1.9839 & $87 \%$ & $7 \%$ & 1 & 0.00430 \\
\hline Neuquen & Sur & $3.1 \%$ & $7 \%$ & $40 \%$ & $12 \%$ & $2 \%$ & $1 \%$ & $2 \%$ & 1.8866 & $85 \%$ & $8 \%$ & 1 & 0.00032 \\
\hline Rio Negro & Sur & $1.3 \%$ & $9 \%$ & $38 \%$ & $10 \%$ & $1 \%$ & $1 \%$ & $2 \%$ & 1.1274 & $87 \%$ & $7 \%$ & 0 & 0.00083 \\
\hline Santa Cruz & Sur & $1.7 \%$ & $5 \%$ & $36 \%$ & $1 \%$ & $1 \%$ & $1 \%$ & $1 \%$ & 1.8616 & $83 \%$ & $9 \%$ & 0 & 0.00671 \\
\hline Tierra del Fuego & Sur & $0.8 \%$ & $34 \%$ & $37 \%$ & $14 \%$ & $1 \%$ & $1 \%$ & $2 \%$ & 6.6035 & $81 \%$ & $12 \%$ & 1 & 0.00130 \\
\hline
\end{tabular}

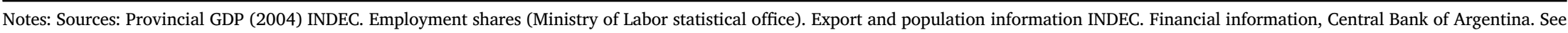
Table 2 for sources. 
Table 2

Variable description and sources.

\begin{tabular}{lll}
\hline State/Regional Model & Source & Seasonally adjusted \\
\hline Industrial employment data & Ministry of Labor & Yes \\
Population Data & INDEC & Yes \\
Macro Variables & INDEC & Yes \\
National GDP & INDEC & No \\
CPI Inflation & BCRA & No \\
$30-59$ days term deposits rate & BCRA & No \\
Bilateral Peso/USD Exchange rate & & \\
\hline Bayesian Model Averaging & & \\
\hline Production Mix & Ministry of Labor & Yes \\
Industry formal employment & Ministry of Labor & Yes \\
Services formal employment & Ministry of Labor & Yes \\
Public Sector formal employment & INDEC & No \\
Large firm pct. & INDEC & No \\
Small firms pct & & \\
Provincial Economy & INDEC & Yes \\
GDP p.c. & INDEC & No \\
Exports p.c. & & \\
Financial Sector & BCRA & No \\
Loans $\%$ & BCRA & No \\
Deposits $\%$ & BCRA & No \\
Branches $\%$ & BCRA & No \\
Brances per capita & BCRA & No \\
Public Bank & & \\
\hline
\end{tabular}

Notes: INDEC: Instituto Nacional de Estadísticas y Censos (National Statistical Office), BCRA: Central Bank of Argentina.

\section{3description. Data}

\subsection{Brief description of Argentina's regional structure}

Argentina is a federal country, with 23 provinces and a semi-autonomous city, Ciudad Autónoma de Buenos Aires. As a federation, provinces reserve all powers not delegated to the federal government. They can dictate their own constitutions and manage autonomous budget and public policies (e.g. education, health) collecting local turnover, property and stamp taxes. Although the national constitution contemplates the possibility that provinces agree to be grouped into regions, the basic institutional jurisdiction is always the provincial level. Regions are nevertheless a common (and historical) way to group and analyze at a subnational level. ${ }^{3}$ In general, they are selected by geographical contiguity, historical traditions and economic and financial similarities. ${ }^{4}$ Fig. 1 shows a traditional regional division that comprises six different regions: Centro, NOA (North-West), NEA (North-East), Cuyo, Sur, and the Buenos Aires metropolitan region, that comprises the city of Buenos Aires and its metropolitan area (Ciudad Autónoma de Buenos Aires plus Gran Buenos Aires, GBA-CABA). We consider GBA-CABA as a different spatial unit because they have considerable economic and structural differences in relation to the rest of the country, and in the Argentinean case, they concentrate a considerable portion of economic activity and population. Together the 6 regions are used in the regional model $(R M)$ described above.

As can be seen in Table 1, provinces included in the Centro (34\% GDP) and GBA-CABA (40\% GDP) regions are the more economic developed provinces. The NEA (4.2\% GDP) and to a lesser extent, the NOA (6.9\% of GDP) provinces are the less developed ones. Whereas the Cuyo $(6,1 \%$ of GDP) region includes provinces with an intermediate level of economic development. Finally, the Patagonian Sur region (9.2\% GDP) includes intermediated developed provinces with large areas and low population density.

\subsection{Variables used in the econometric models}

Table 2 describes the data used and its sources. All variables have quarterly periodicity, and the time span considered for our exercises is 2003q1-2017q2. The series were seasonally adjusted (when needed) using X-13 ARIMA-SEATS, detrended or differentiated to make them stationary and finally log transformed. Population data between Census was interpolated using a linear polynomial.

One of the major issues working with Argentina is the lack of good data. At the regional and provincial level we can only rely on employment (total formal employment) to construct a panel data from which we can study the spatial interactions. The macro variables (consumer's price index CPI, US dollar/peso exchange rate and GDP) as well as the 'spatial variable' are in logarithm, the interest rate (30-59 days term deposits rate) is in percentage. After these transformations, based on augmented Dickey-Fuller tests, all variables are

\footnotetext{
${ }^{3}$ See for instance the National Production Ministry, http://mapaprod.produccion.gob.ar.

${ }^{4}$ See, for instance, Elosegui, Anastasi, Sangiácomo, and Blanco (2010) for an analysis of economic determinants of use and availability of banking services at a local level for the 1998-2009 period.
} 

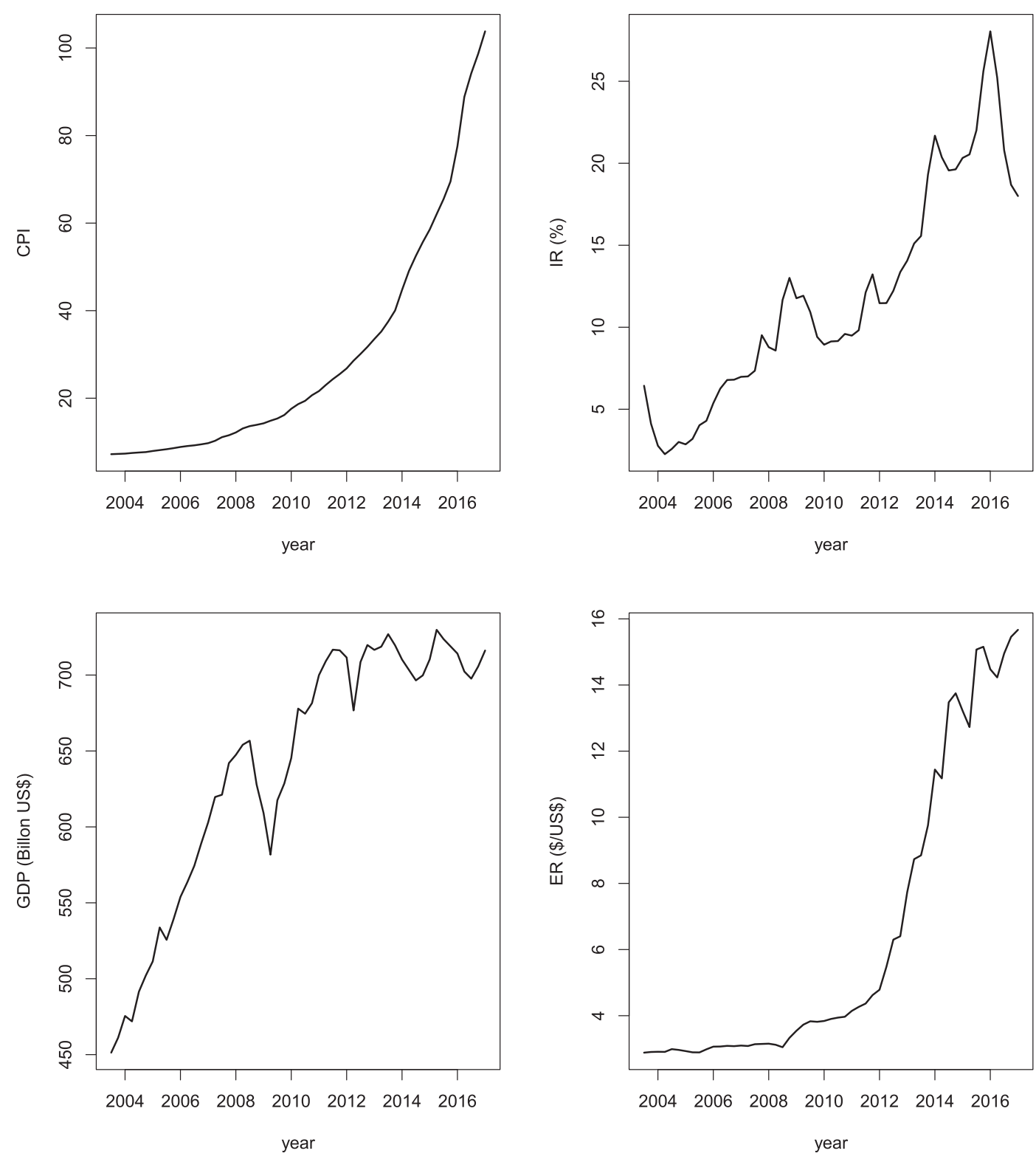

Fig. 2. Macro variables.

Table 3

Estimates of $\phi_{01}$ and $\phi_{11}$ for RM.

\begin{tabular}{lllllll}
\hline & Centro & Cuyo & CABA-GBA & NEA & NOA & Sur \\
\hline$\phi_{0}$ & 0.619 & 0.749 & 0.464 & -0.969 & 0.895 & 0.684 \\
& $(0.146)^{* * *}$ & $(0.296)^{* * *}$ & $(0.123)^{* * *}$ & $(0.506)^{* *}$ & $(0.136)^{* * *}$ & $(0.240)^{* * *}$ \\
$\phi_{1}$ & 0.662 & 0.388 & 0.154 & 0.399 & 0.558 & 0.918 \\
& $(0.198)^{* * *}$ & $(0.290)^{*}$ & $(0.147)$ & $(0.384)$ & $(0.259)^{* * *}$ & $(0.254)^{* * *}$ \\
\hline
\end{tabular}

Notes: Bootstrap standard errors in parenthesis. *Significant at 0.2 level. **Significant at 0.1 level. ***Significant at 0.05 level. The estimates of $\phi_{21}$ are only significant for CABA-GBA, Sur and NEA at 0.2 level. 
Table 4

Estimates of $\phi_{01}$ and $\phi_{11}$ for SM.

\begin{tabular}{|c|c|c|c|c|c|}
\hline States & $\phi_{01}$ & $\phi_{11}$ & States & $\phi_{01}$ & $\phi_{11}$ \\
\hline Buenos Aires & $\begin{array}{l}0.263 \\
(0.833)\end{array}$ & $\begin{array}{l}-0.039 \\
(1.316)\end{array}$ & Mendoza & $\begin{array}{l}0.451 \\
(0.118)^{* * * *}\end{array}$ & $\begin{array}{l}0.699 \\
(0.211)^{* * *}\end{array}$ \\
\hline Córdoba & $\begin{array}{l}0.330 \\
(0.162)^{* * *}\end{array}$ & $\begin{array}{l}0.197 \\
(0.126)^{*}\end{array}$ & Misiones & $\begin{array}{l}0.171 \\
(0.078)^{* * *}\end{array}$ & $\begin{array}{l}0.276 \\
(0.124)^{* * *}\end{array}$ \\
\hline Catamarca & $\begin{array}{l}0.979 \\
(0.285)^{* * * *}\end{array}$ & $\begin{array}{l}0.438 \\
(0.316) *\end{array}$ & Neuquén & $\begin{array}{l}0.852 \\
(0.193)^{* * * *}\end{array}$ & $\begin{array}{l}0.344 \\
(0.300)\end{array}$ \\
\hline Chaco & $\begin{array}{l}0.566 \\
(0.468)\end{array}$ & $\begin{array}{l}0.467 \\
(0.472)\end{array}$ & Río Negro & $\begin{array}{l}0.237 \\
(0.138)^{* *}\end{array}$ & $\begin{array}{l}0.424 \\
(0.158)^{* * *}\end{array}$ \\
\hline Chubut & $\begin{array}{l}0.420 \\
(0.114)^{* * *}\end{array}$ & $\begin{array}{l}0.263 \\
(0.205) *\end{array}$ & Salta & $\begin{array}{c}-0.088 \\
(0.153)\end{array}$ & $\begin{array}{c}-0.097 \\
(0.226)\end{array}$ \\
\hline GBA-CABA & $\begin{array}{l}0.001 \\
(0.034)\end{array}$ & $\begin{array}{l}0.015 \\
(0.024)\end{array}$ & San Juan & $\begin{array}{l}0.172 \\
(0.072)^{* * *}\end{array}$ & $\begin{array}{l}-0.031 \\
(0.125)\end{array}$ \\
\hline Corrientes & $\begin{array}{l}0.588 \\
(0.129)^{* * *}\end{array}$ & $\begin{array}{l}0.670 \\
(0.218)^{* * * *}\end{array}$ & San Luis & $\begin{array}{l}0.272 \\
(0.140)^{* *}\end{array}$ & $\begin{array}{l}0.225 \\
(0.205)\end{array}$ \\
\hline Entre Ríos & $\begin{array}{l}0.301 \\
(0.062)^{* * *}\end{array}$ & $\begin{array}{l}0.171 \\
(0.097)^{* *}\end{array}$ & Santa Cruz & $\begin{array}{l}0.982 \\
(0.287)^{* * *}\end{array}$ & $\begin{array}{c}-0.065 \\
(0.325)\end{array}$ \\
\hline Formosa & $\begin{array}{l}0.513 \\
(0.287)^{* * *}\end{array}$ & $\begin{array}{l}0.072 \\
(0.402)\end{array}$ & Santa Fe & $\begin{array}{l}0.150 \\
(0.110)^{*}\end{array}$ & $\begin{array}{l}0.340 \\
(0.118)^{* *}\end{array}$ \\
\hline Jujuy & $\begin{array}{l}0.131 \\
(0.074)^{* *}\end{array}$ & $\begin{array}{l}0.135 \\
(0.138)\end{array}$ & Santiago del Estero & $\begin{array}{l}-0.141 \\
(0.129)\end{array}$ & $\begin{array}{l}-0.198 \\
(0.393)\end{array}$ \\
\hline La Pampa & $\begin{array}{l}0.247 \\
(0.163)^{* *}\end{array}$ & $\begin{array}{l}0.351 \\
(0.265) *\end{array}$ & Tierra del Fuego & $\begin{array}{l}-0.625 \\
(0.198)^{* * *}\end{array}$ & $\begin{array}{l}0.320 \\
(0.158)^{* * *}\end{array}$ \\
\hline La Rioja & $\begin{array}{l}-0.126 \\
(0.255)\end{array}$ & $\begin{array}{l}0.930 \\
(0.541)^{* *}\end{array}$ & Tucumán & $\begin{array}{l}0.506 \\
(0.160)^{* * * *}\end{array}$ & $\begin{array}{l}0.417 \\
(0.325)^{*}\end{array}$ \\
\hline
\end{tabular}

stationary. Fig. 2 plots the main macroeconomic variables. ${ }^{5}$

For our subsequent analysis (see section 5 for the Bayesian model averaging analysis) we add to employment and macro data three sets of subnational indicators: one that captures the production mix of the province, and other that is specific to the stance of the provincial economy and the last that accounts for financial sector indicators (see Table 1).

\section{Empirical results}

\subsection{Spatial correlation estimates}

The spatial SVAR models proposed here depends on the existence of spatial effects. Such interaction is captured by the coefficients $\phi_{h k}$, where $h$ refers to the temporal lag and $k$ refers to the lag order of the contiguity matrix, we use $h=0,1,2$ and $k=1$. If $\phi_{0 k}^{n} \neq 0$, with $n=(1, \ldots, N)$, that means that a change in employment in the neighborhood of spatial unit $n$ has a (direct) contemporaneous impact on employment of unit $n$. Furthermore, given that all spatial units are, directly or indirectly connected, a change in employment in any spatial unit has a (direct or indirect) contemporaneous impact on employment of all other spatial units. This multiplicative impacts depend on the value (and significance) of $\phi_{h k}^{n}$. This is also valid for $\phi_{1 k}^{n}$ and $\phi_{2 k}^{n}$, but now the impact is with one and two time lags respectively.

Tables 3 and 4 present the point estimates and the bootstrap standard errors (with 200 bootstrap simulations) of the estimates of $\phi_{h k}$ for the Regional and State models, respectively. The analysis confirms that most spatial effects are statistically significant and positive with a few exceptions.

\subsection{Regional and non-spatial aggregate models}

Figs. 3 and 4 summarize the IRFs from a monetary shock (a 1\% increment in the interest rate) at under both the regional level (using the $R M$ model) the non-spatial national aggregate models. A simple comparison shows that most regions show a negative effect when the interest rate increases, except for the NEA region (where the effect is not statistically significant). There is however a marked heterogeneity in the effects. The Sur and Cuyo regions are the most affected. Note that the IRF for the non-spatial model does not correspond to a simple average of the others, although it is close to the GBA-CABA region (the largest and most concentrated region).

As a comparison we also compute the effect of the same monetary shock on employment, for each region separately (see Fig. 5). The

\footnotetext{
${ }^{5}$ Constructing appropriate data for Argentina for the 2007-2015 period is a controversial issue. First, during those years the official statistical office (INDEC, Instituto Nacional de Estadísticas y Censos) has been manipulated to report lower inflation. Nevertheless, we use the official CPI. Preliminary evidence using other alternative CPI provide the same results. Second, the 2011-2015 period is one of exchange rate controls. Thus, the official exchange rate (OER) differed from the unofficial exchange rate (UER) also known as "blue". The former applied to imports and exports, but most economic agents had quantity restrictions on buying US dollars and could only could buy dollars at the unofficial market. We use the OER for our analysis.
} 


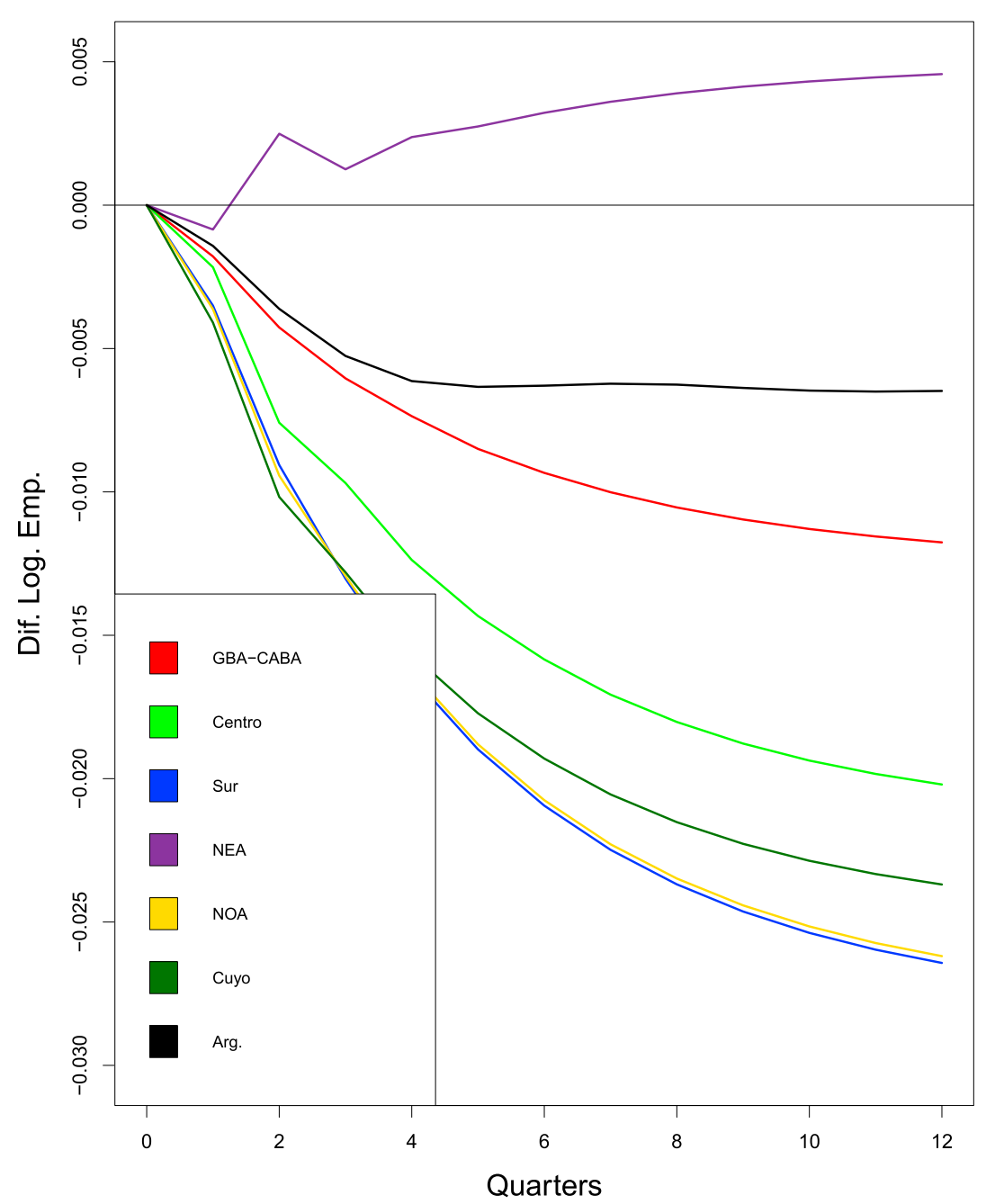

Fig. 3. IRFs for national and regional model. Note: IRFs of a $1 \%$ increment in the interest rate using the national aggregate VAR model and the RM spatial model.

results confirm the negative impact of increasing the interest rate on employment. These results confirm that monetary shocks have a negative impact on regional employment. Note, however, that the $R M$ spatial model produces larger effects than what is captured by each region separately. While the separate VAR has effects ranging between -0.003 and -0.008 , the $R M$ model ranges from -0.010 to -0.025 (ignoring the positive NEA effect). The ranking among regions also changes. While GBA-CABA has the largest effect when considering by a separate VAR, it the smallest effect (in absolute value) in the RM estimation.

\subsection{State model}

Consider now the IRFs from a monetary shock at the provincial level. These results are summarized in figures (6)-(8). This analysis shows greater heterogeneity among provinces. Many of them are not statistically significant although the point estimate is negative.

First, most short- and long-term effects are negative, except for Neuquén, Santiago del Estero and Tierra del Fuego. Thus, increasing the interest rate has a negative impact on employment growth at the Argentinean states.

Second, most of them have a short term negative and significant effect. Exceptions are CABA-GBA and Buenos Aires provinces. This could be due to the limited nature of our database because the national level estimate is indeed significant, and both units have a large share of the national aggregate total employment.

Third, for those provinces with a long-term statistically significant effect, employment growth decreases by between $1 \%$ and $2 \%$ after a 1 percentage point increment in the interest rate.

Figure ?? compute the effect of the monetary policy shock on GDP for this model. The long-term effect is negative, although not statistically significant. 
(a) Centro

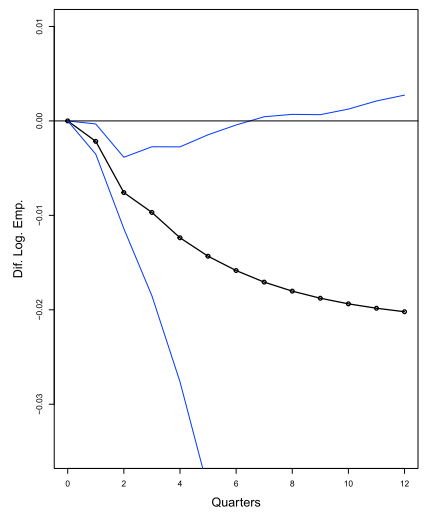

(d) NEA

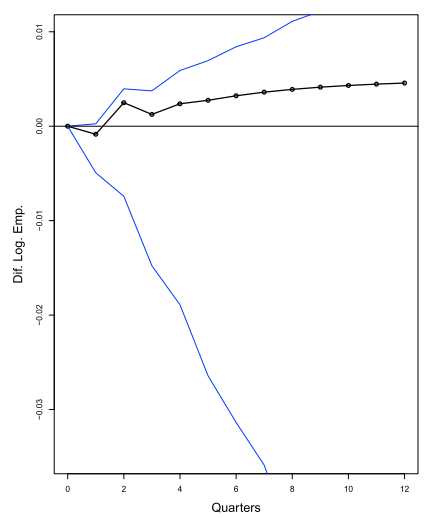

(b) Cuyo

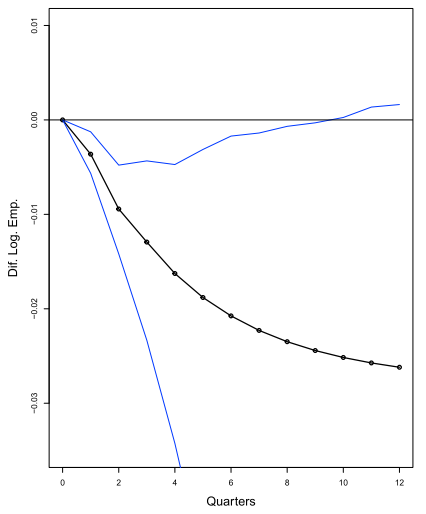

(e) NOA

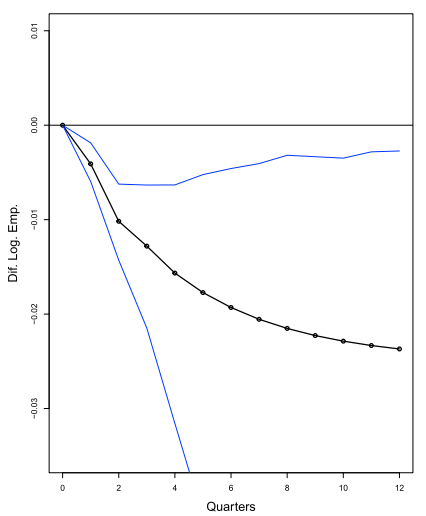

(c) GBA-CABA

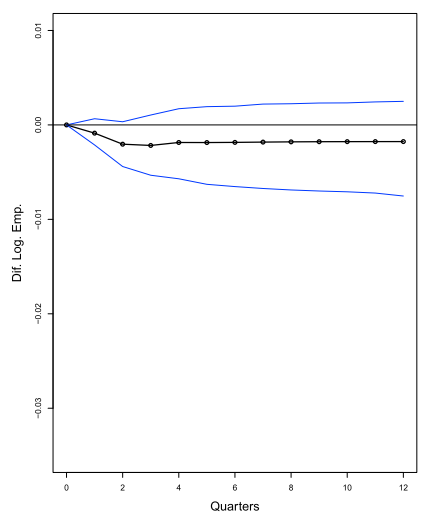

(f) Sur

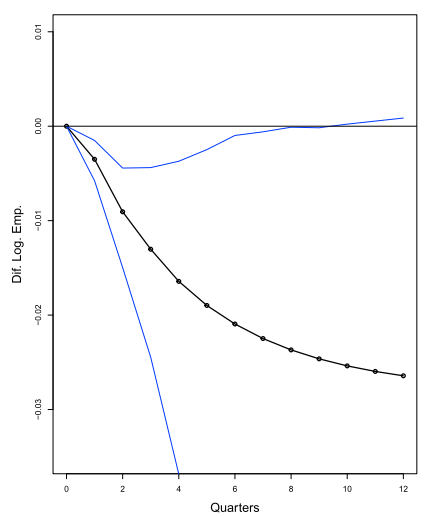

Fig. 4. IRFs by Regions. Note: IRFs of a $1 \%$ increment in the interest rate using the $R M$ spatial model. $80 \%$ confidence interval are reported using bootstrap with 200 repetitions.

\section{Analyzing the asymmetric responses}

The evidence from the IRFs analysis indicates that the Argentinean provinces have different sensitivity to monetary policy shocks. Albeit in a preliminary way, it is interesting to study those characteristics of the provinces that could explain this heterogeneity. The economic literature analyzing the transmission channels of monetary policy indicates that the structure of the financial and/or productive sector are key. Indeed, the provinces could react differently to a monetary shock depending on the scope of the local financial services and their productive economic structure. Also, the availability and/or competition of financial services may have differential impacts on the regions. In addition, prevailing productive sectors might have different dependence on financial services (i.e., external lending, cash management), cushioning or increasing the effect of monetary shocks. In order to take into account these aspects, the different accumulative impulse responses can be contrasted with the average characteristics of the provinces in different economic and financial dimensions. However, with only 24 variables to explain and numerous potentially explanatory factors there is an interesting methodological challenge. In such cases, empirical applications use the Bayesian model averaging (BMA).

The BMA method allows contrasting different combination of models and select the most relevant explanatory variables. As Serrano and Nakane (2015) we follow Zeugner (2011) to apply the BMA empirical methodology. This methodology provides a tool to approximate the true model of the data when there is a high number of covariates that could influence the dependent variable. A Bayesian criterion is applied to evaluate which would be the regressors to be included in the analysis, by selecting the models and regressors that imply a greater likelihood. Analyzing a large number of models, via a Markov chain Monte Carlo (MCMC) methodology, the relevant variables are estimated with different combinations of models for different priors (see BMS package). Each model can then be weighted and its variables introduced in the final model as a weighted average of the parameters of each estimated model. In this way some variables will have zero weight in the final model, while others will be more likely as an explanatory variable of the model.

We estimate two models using (i) accumulated and (ii) maximum IRS for 10 periods as our dependent variables. Only statistically significant shocks were considered (non-significant shocks are assigned a value of zero). The independent variables are 18 , including 


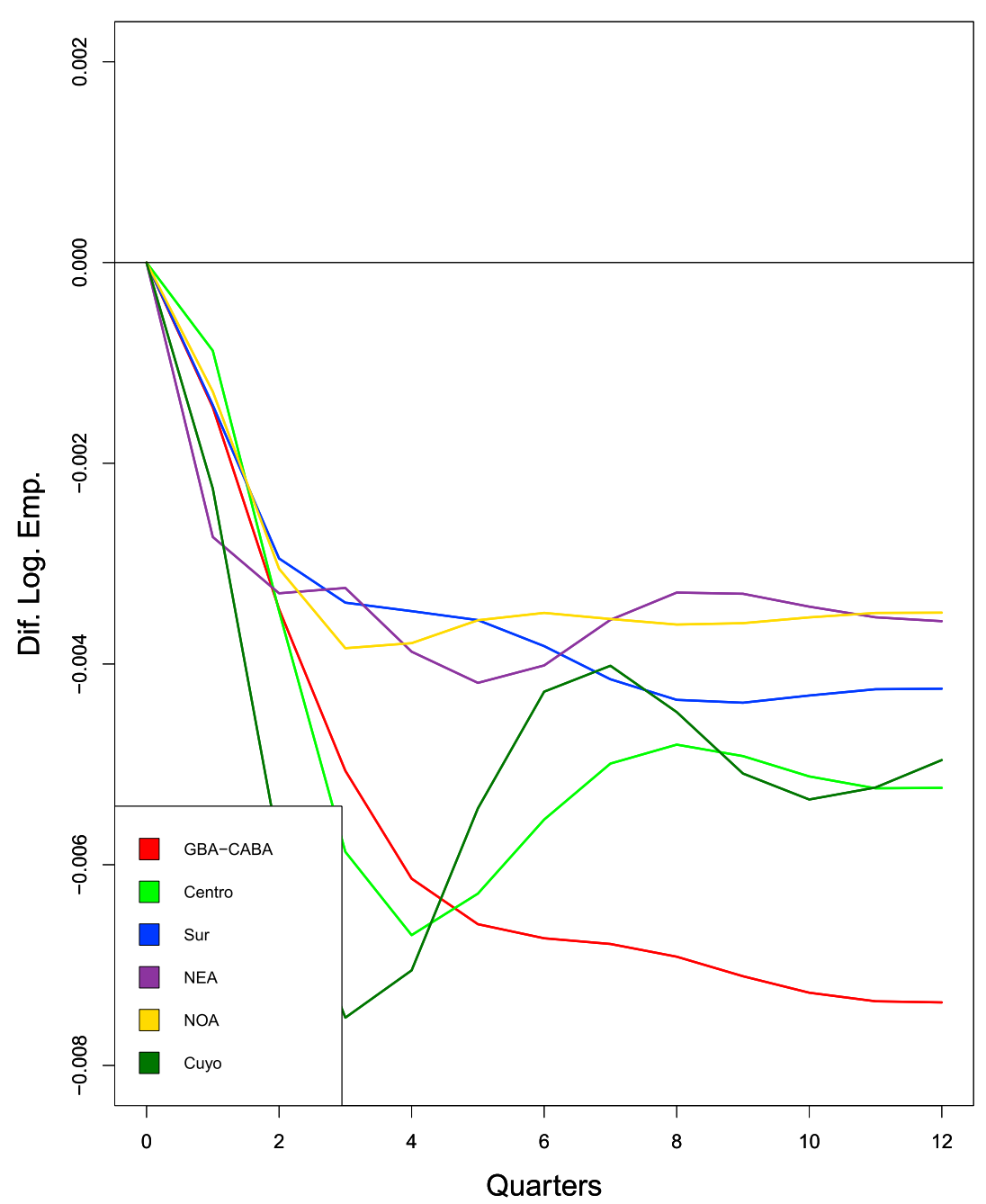

Fig. 5. IRFs for each region separately VAR model. Note: IRFs of a $1 \%$ increment in the interest rate in a VAR model, separately for each region.

indicators of the productive mix, the scope and outreach of financial services and the overall provincial economic activity. Table 5 shows the results of implementing both models. The PIP column indicates the probability of inclusion of a row variable. Column Post. Mean indicates the posterior mean coefficient (and sign) corresponding to the variable and the next column shows the posterior standard deviation. The last column is the probability of posterior sign change. Results indicate that the most common model has a maximum of six explanatory variables. The posterior distribution probability analyzed through MCMC determines that not more than three or four variables concentrate most of the weights and would be part of the selected model.

In general, the PIP effects are below 60\% indicating a relative uncertainty on the importance of the covariation variables. The availability of branches per capita is the most significant variable. The provinces of greater financial development seems to have lower relative differential impacts -possibly linked to higher levels of competition in such services. On the other hand, greater sensitivity to monetary shocks are related to the share of formal employment in the industry. Likewise, formal employment in services show a positive differential impact.

The results are in line with the findings of other empirical studies. In fact, the seminal paper of Carlino and DeFina (1999) for US. indicates that manufacture intensive regions are more sensitive to changes in monetary policies than more industrially diverse regions. In addition, regions with larger concentration of small firms tend to be more responsive to such shocks. Arnold (2001) finds that a well diversified economic structure contributes to minimize the impact of monetary shocks in Europe. Authors, like Von Hagen and Waller (2000) also encountered that sensitivity reduces as small banks participation in the region increases. On the other hand, Serrano and Nakane (2015) found that employment on transformation industry presents the main PIP in the case of Brazil. Commercial employment and branches per capita are other significant variables. In the case of Sweden, Runnemark (2012) found similar results: regions with negative responses have, on average, a larger share of employment in the industrial sector, a larger share of small firms and, unlike the Argentinean case, a smaller share of employment in the service sector. Ridhwan et al. (2014) found similar results for Indonesia regarding the importance of the industrial sector. Whereas for the Netherlands, Arnold and Vrugt (2002) conclude that construction 
(a) Buenos Aires (Centro)

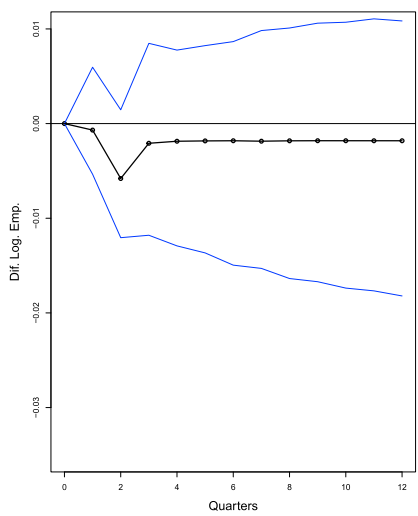

(d) Chubut (Sur)

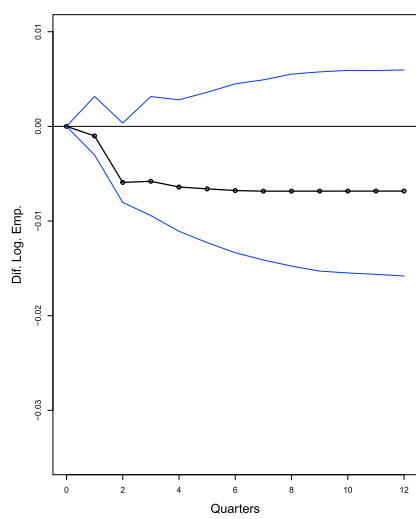

(g) Entre Ríos (Centro)

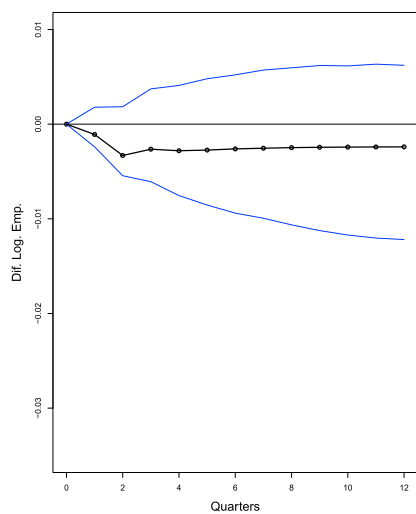

(b) Catamarca (NOA)

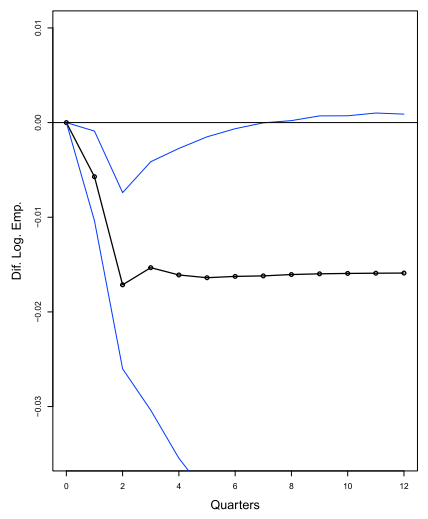

(e) Córdoba (Centro)

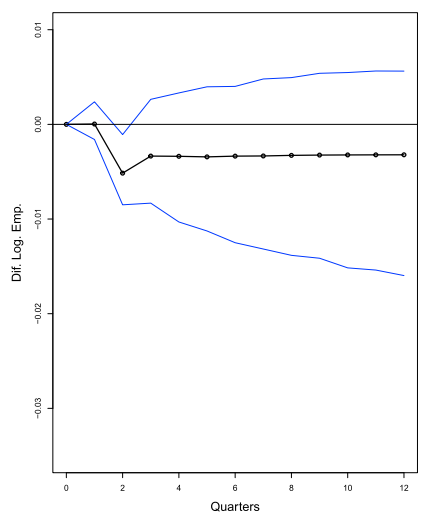

(h) Formosa (NEA)

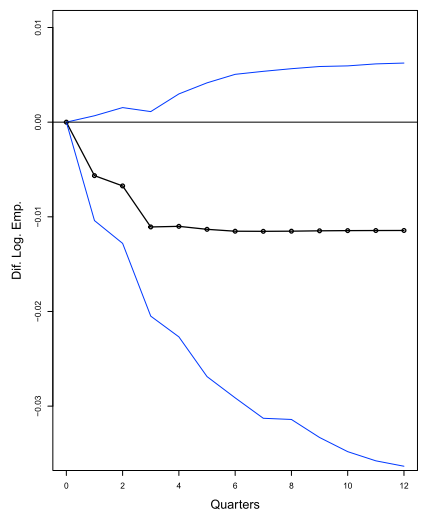

(c) Chaco (NEA)

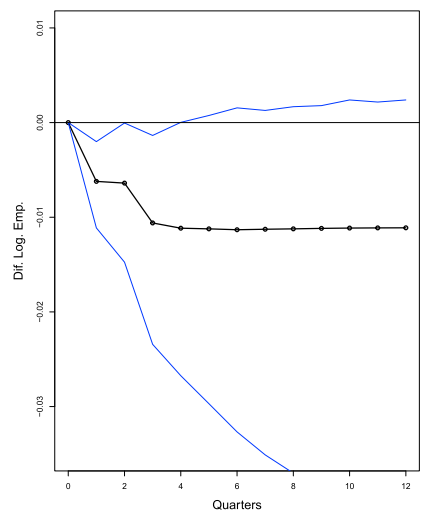

(f) Corrientes (NEA)

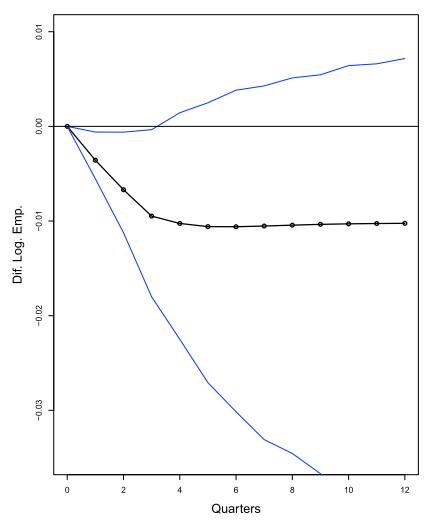

(i) GBA-CABA

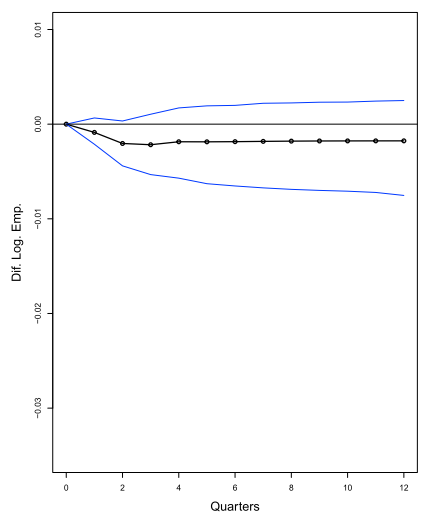

Fig. 6. IRFs by states. Note: IRFs of a $1 \%$ increment in the interest rate using the $S M$ spatial model. $80 \%$ confidence interval are reported using bootstrap with 200 repetitions. 
(a) Jujuy (NOA)

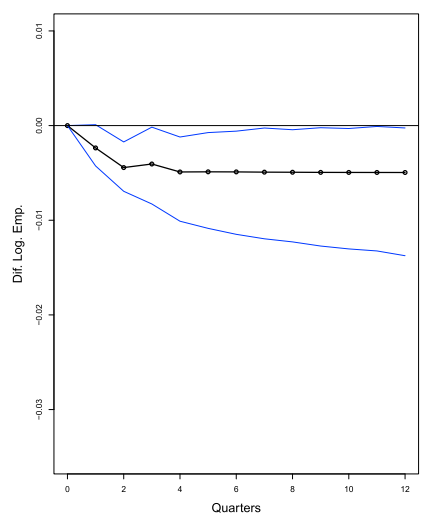

(d) Mendoza (Cuyo)

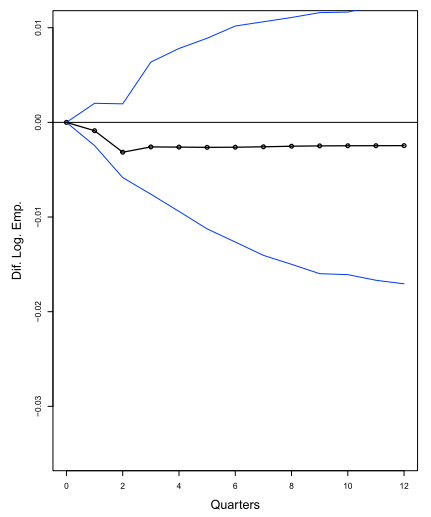

(g) Río Negro (Sur)

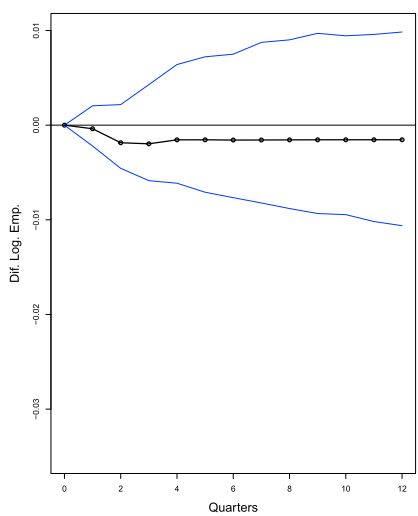

(b) La Pampa (Centro)

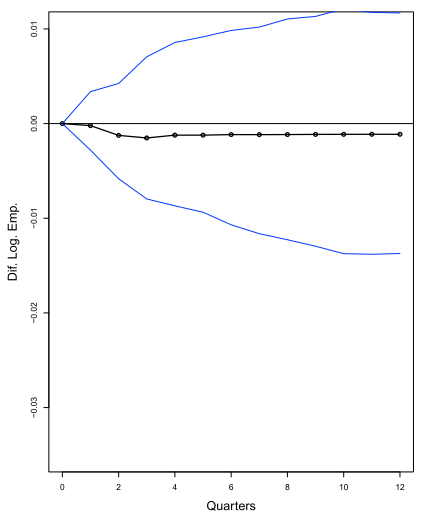

(e) Misiones (NEA)

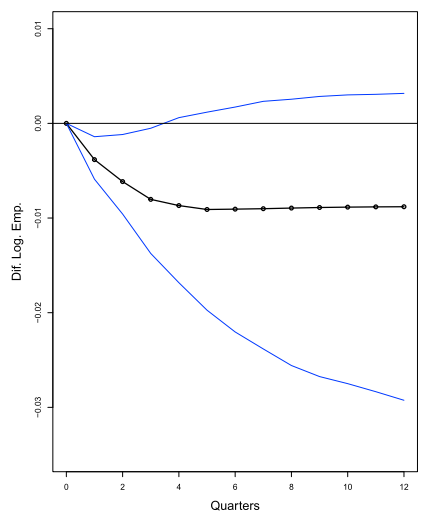

(h) Salta (NOA)

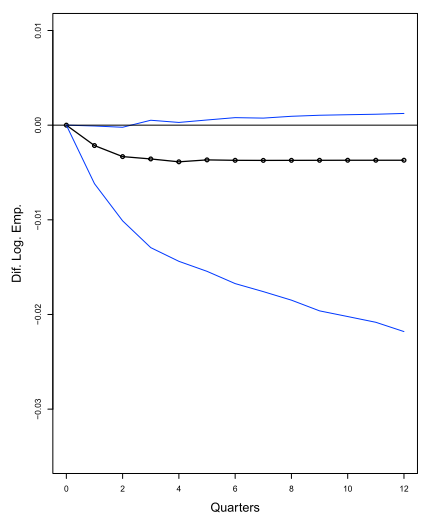

(c) La Rioja (NOA)

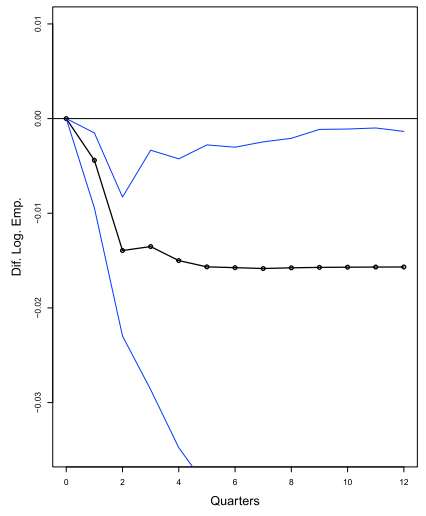

(f) Neuquén (Sur)

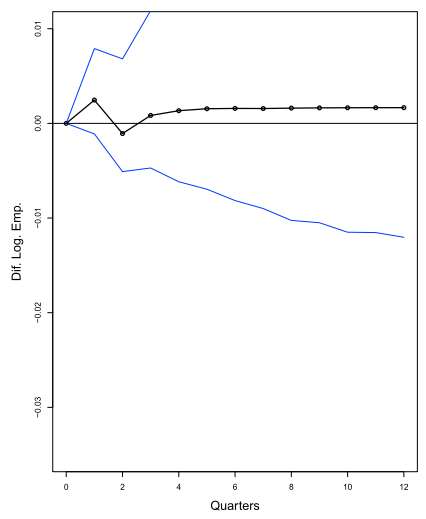

(i) San Juan (Cuyo)

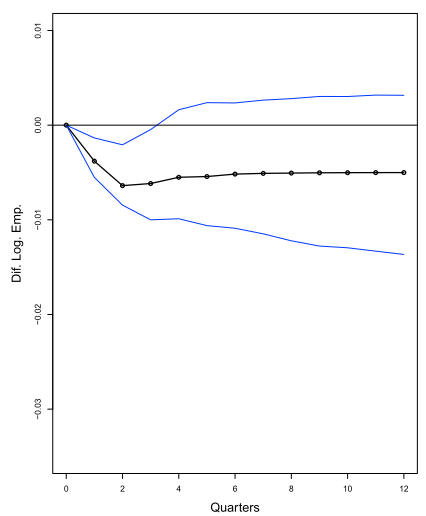

Fig. 7. IRFs by state. Note: IRFs of a $1 \%$ increment in the interest rate using the $S M$ spatial model. $80 \%$ confidence interval are reported using bootstrap with 200 repetitions. 
(a) San Luis (Cuyo)

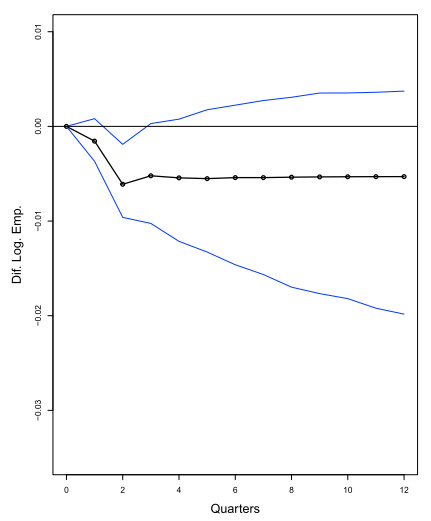

(d) Santiago del Estero (NOA)

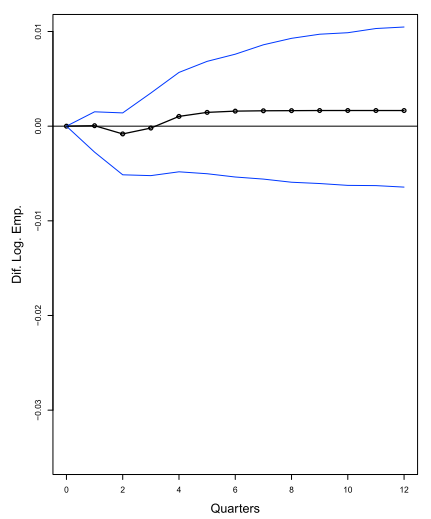

(b) Santa Cruz (Sur)

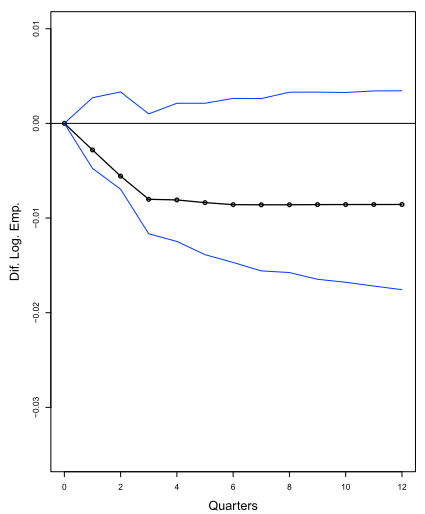

(e) Tierra del Fuego (Sur)

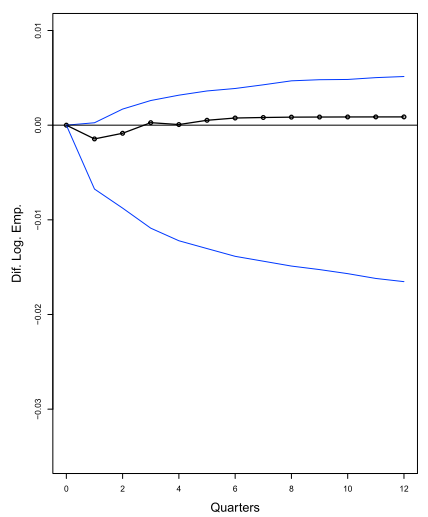

(c) Santa Fe (Centro)

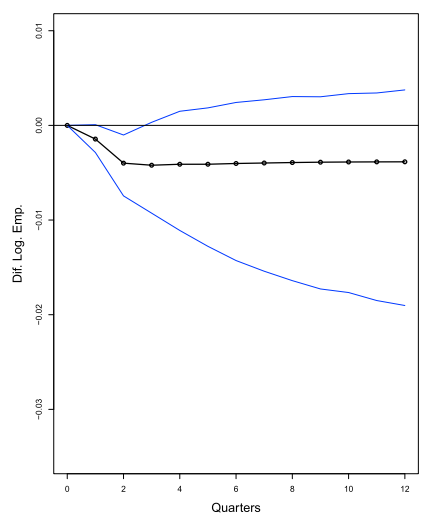

(f) Tucumán (NOA)

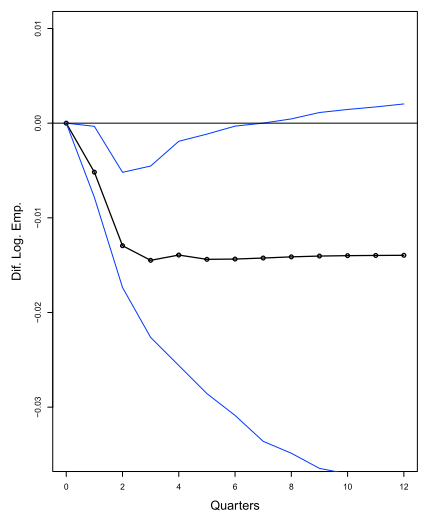

Fig. 8. IRFs by state. Note: IRFs of a $1 \%$ increment in the interest rate using the $S M$ spatial model. $80 \%$ confidence interval are reported using bootstrap with 200 repetitions.

Table 5

Bayesian model averaging results.

\begin{tabular}{|c|c|c|c|c|c|c|c|c|}
\hline & \multicolumn{4}{|c|}{ Accummulative Impulse Response (10 periods) } & \multicolumn{4}{|c|}{ Maximum Impulse Response (10 periods) } \\
\hline & PIP & Post. Mean & Post. S.D. & Cond. Pos. Sign & PIP & Post. Mean & Post. S.D. & Cond. Pos. Sign \\
\hline \multicolumn{9}{|l|}{ Production Mix } \\
\hline Industry formal emp & 0.2397 & 0.310 & 0.920 & 1.000 & 0.256 & 0.380 & 1.033 & 1.000 \\
\hline Services formal emp & 0.2857 & 1.002 & 2.486 & 0.910 & 0.295 & 1.135 & 2.699 & 0.910 \\
\hline Public formal emp & 0.1816 & 0.260 & 1.561 & 0.890 & 0.178 & 0.230 & 1.605 & 0.860 \\
\hline Large firm pct & 0.2172 & 0.750 & 4.540 & 0.890 & 0.212 & 0.800 & 4.677 & 0.910 \\
\hline $\begin{array}{l}\text { Small firms pct } \\
\text { Provincial Economy }\end{array}$ & 0.2239 & -0.880 & 3.806 & 0.020 & 0.212 & -0.740 & 3.820 & 0.030 \\
\hline GDP p.c. & 0.2449 & -1.099 & 4.335 & 0.050 & 0.242 & -1.101 & 4.408 & 0.060 \\
\hline $\begin{array}{l}\text { Exports p.c. } \\
\text { Financial Sector }\end{array}$ & 0.1782 & -3.891 & 3.037 & 0.120 & 0.178 & -3.891 & 3.037 & 0.120 \\
\hline Loans p.c. & 0.2139 & 0.080 & 3.861 & 0.210 & 0.217 & 0.000 & 3.897 & 0.170 \\
\hline Deposits p.c. & 0.2170 & -0.460 & 3.805 & 0.040 & 0.220 & -0.450 & 3.874 & 0.020 \\
\hline Branches p.c. & 0.5183 & -0.0700 & 0.0900 & 0.0000 & 0.506 & -0.080 & 0.100 & 0.000 \\
\hline Brances pct & 0.2031 & -0.070 & 1.445 & 0.230 & 0.201 & -0.080 & 1.471 & 0.210 \\
\hline Public Bank & 0.2009 & 0.020 & 0.130 & 0.630 & 0.202 & 0.020 & 0.140 & 0.630 \\
\hline
\end{tabular}


activity in conjunction with oil and gas sector lead to more interest rate sensitivity within a region.

\section{Discussion and conclusion}

This paper empirically investigates how economic activity, as measured by total formal employment in Argentina at regional and provincial (i.e., state) levels respond to central or national monetary policy shocks, given by a change in the policy interest rate. The results confirm that there is considerable regional heterogeneity across regions and states within Argentina, resulting in differential effects of monetary policy shocks. At the regional level the long-term effects are negative and statistically significant. At the provincial level, 11 provinces show a negative and significant long-term impact of the shock on the interest rate over employment. However, there are 13 provinces in which the effect is not statistically significant, including GBA-CABA and Buenos Aires province.

Macroeconomic policies are generally "blind" at regional level (Hewings, 2014) and this ignores potentially large asymmetric effects across regions. The results in this paper indicate that further research should be applied benefiting from the large literature on spatial analysis of macroeconomic effects.

The non-homogeneous synchronization of regional business cycles may also be an important factor for the observed heterogeneity of regional impact of monetary shocks. In fact, local or regional cycles may not be in phase, with other regions or the national economy. In this sense, the time window and the territorial unit of analysis may be crucial to understand the potential heterogeneity.

Indeed, high frequency data may augment the heterogeneity by capturing better region to region interaction, as documented by Park and Hewings (2012). Given our short time span we focused on quarterly data that is at the same time more relevant to analyze the impact of monetary policy considering the traditional implementation lag of monetary policy shocks. Also, the authors showed that different industry mix and/or the place in the value chain production may contribute to the cyclical asymmetries, in line with the importance of such characteristics for the monetary policy transmission mechanism literature.

As Dominguez-Torres and Hierro (2019) emphasize, not only the time domain but also the space domain is important when considering cyclical heterogeneities. Asymmetries can be traced back to the interaction between regions, or more likely between provinces within the regions. The authors reviewed several empirical studies having comparable results with different aggregation levels both in terms of qualitative (trajectory) and quantitative (magnitude) results. In the case of US and China, authors find that the results are broadly maintained when using different levels of territorial aggregation. However, in the cases of Brazil and Canada, there are no such regularities and consistencies among the empirical analysis when using different levels of territorial aggregation. See also Mejía and Lucatero (2011) for the case of Mexico.

It should be noted that as an initial methodological approach to the provincial business cycle in Argentina, we focus on the impact of a macroeconomic shock (monetary policy) to the regions or provinces considering the spatial interactions. However, as noted by an anonymous referee, our next research agenda should include at least two interesting issues. First, a better distinction between aggregated shocks and local to local shocks. Despite been an active research agenda for developed federal countries, there are not much research in developing federal countries. For instance, Bai and Wang (2012) was used by Chung (2016) and Chung and Hewings (2015) to capture regional asymmetries using a multi-level (in this case, two-level) approach. Along the same lines, Ramajo et al. (2017) developed a multiregional spatial vector autoregressive (MultiREG-SpVAR) model applied to study the spatiotemporal transmission of macroeconomic shocks across the regions in Spain. Second, our results indicate that the nation influences regions and there is some "contamination" from other regions but the strength and direction of these effects are not fully revealed as in the work by Hayashida and Hewings (2009) or through the Dendrinos-Sonis log-linear relative dynamic approach applied by Postiglione and Hewings (2008) for the case of Italy.

Notes: Bootstrap standard errors in parenthesis. *Significant at 0.2 level. **Significant at 0.1 level. ***Significant at 0.05 level. The estimates of $\phi_{21}$ are only significant for Mendoza and San Juan at 0.05 level and for Tierra del Fuego and for Santa Fe at 0.1 and 0.2 level respectively.

\section{References}

Anastasi, A., Blanco, E., Elosegui, P., \& Sangiácomo, M. (2010). Bankarization and determinants of availability of banking services in Argentina. Ensayos Economicos, 60. Anselin, L. (1998). Spatial econometrics: Models and applications. Dordrecht, The Netherlands: Kluwer.

Arnold, I. (2001). Regional effects of monetary policy in Europe. Journal of Economic Integration, 16(3), 399-420.

Arnold, I., \& Vrugt, E. (2002). Regional effects of monetary policy in The Netherlands. International Journal of Business and Economics, 1(2), $123-134$.

Bai, J., \& Wang, P. (2012). Identification and estimation of dynamic factor models. New York: Department of Economics, Columbia University. Discussion Paper No. 111206.

Bernanke, B., \& Blinder, A. (1988). Credit, money, and aggregate demand. NBER Working Paper No. 2534, March.

Bertanha, M., \& Haddad, M. A. (2008). Efeitos regionais da política monetéria no Brasil: Impactos e transbordamentos espaciais. Revista Brasileira de Economia, 62(1), 3-29.

Carlino, G. A., \& DeFina, R. (1998). The differential regional effects of monetary policy. The Review of Economics and Statistics, $80,572-587$.

Carlino, G. A., \& DeFina, R. (1999). The differential effects of monetary policy: Evidence from US States and Regions. Journal of Regional Science, 39, 339-358.

Christiano, L., Eichenbaum, M., \& Evans, C. (1996). The effects of monetary policy shocks: Evidence from the flow of funds. The Review of Economics and Statistics, 78, $16-34$.

Chung, S. (2016). Assessing the regional business cycle asymmetry in a multi-level structure framework: A study of the top 20 US MSAs. The Annals of Regional Science, $56,229-252$.

Chung, S., \& Hewings, G. J. D. (2015). Competitive and complementary relationship between regional economies: A study of the Great lake states. Spatial Economic Analysis, 10, 205-229.

De Lucio, J., \& Izquierdo, M. (1999). Local responses to a global monetary policy: The regional structure of financial systems. Fundación de Estudios de Economia Aplicada FEDEA. Documento de Trabajo 99-14.

Di Giacinto, V. (2003). Differential regional effects of monetary policy: A geographical SVAR approach. International Regional Science Review, $26(3), 313-341$. 
Dominguez-Torres, H., \& Hierro, L. (April 2019). The regional effects of monetary policy: A survey of the empirical literature. Journal of Economic Surveys, 33(2), 604-638.

Fraser, P., Macdonald, G. A., \& Mullineux, A. (2014). Regional monetary policy: An Australian perspective. Regional Studies, 48(8), $1419-1433$.

Guo, X., \& Tajul, A. M. (2017). "Regional effects of monetary policy in China: Evidence from China's provinces. Bulletin of Economic Research, 69(2), 178-208.

Hayashida, Motonari, \& Hewings, G. (2009). Regional business cycles in Japan. International Regional Science Review, 32, $110-147$.

Hewings, G. J. D. (2014). Spatially blind trade and fiscal impact policies and their impact on regional economies. The Quarterly Review of Economics and Finance, 54(4), 590-602.

Kashyap, A., \& Stein, J. (1994). The impact of monetary policy on bank balance sheets. NBER Working Paper No. 4821, August.

Kashyap, A., Stein, J., \& Wilcox, D. (1993). Monetary policy and credit conditions: Evidence from the composition of external finance. The American Economic Review, 83, 78-98. Mar.

Martin, R. L., \& Oeppen, J. E. (1975). The identification of regional forecasting models using spacetime correlation functions. Transactions of the Institute of British Geographers, 66, 95-118.

Mejía, P., \& Lucatero, D. (2011). Trends, structural breaks and economic growth regimes in the states of Mexico, 1940-2006. Paradigma Económico, 3(1), 5-36.

Park, Y., \& Hewings, G. J. D. (2012). Does industry mix matter in regional business cycles? Studies in Regional Science, 42, 39-60.

Pfeifer, P. E., \& Bodily, S. E. (1990). A test of space-time ARMA modelling and forecasting of hotel data. Journal of Forecasting, 9 , 255-272.

Pfeifer, P. E., \& Deutsch, S. J. (1980). A three-stage iterative procedure for space-time modeling. Technometrics, $22,35-47$.

Postiglione, P., \& Hewings, G. J. D. (2008). Spatial hierarchical analysis of Italian regions. Journal of Geographical Systems, 10, 369-382.

Ramajo, J., Márquez, M. A., \& Hewings, G. J. D. (2017). Spatiotemporal analysis of regional systems: A multiregional spatial vector autoregressive model for Spain. International Regional Science Review, 40, 75-96.

Ridhwan, M., Groot, H., Rietveld, P., \& Nijkamp, P. (2014). The regional impact of monetary policy in Indonesia. Growth and Change, 45(2), $240-262$.

Runnemark, E. (2012). Regional effects of monetary policy in Sweden. Lund University. Working Paper 2012:9.

Serrano, F., \& Nakane, M. (2015). Impacto regional da política monetaria no Brasil: Uma abordagem Bayesiana. " Department of Economics FEA/USP. Working Paper Series 2015-44.

Stakhovych, S., \& Bijmolt, T. H. A. (2008). Specification of spatial models: A simulation study on weights matrices. Papers in Regional Science, 88(2), 389-408.

Von Hagen, J., \& Waller, C. J. (2000). Regional aspects of monetary policy in Europe. In ZEI studies in European economics and law. Dordrecht, The Netherlands: Kluwer.

Zeugner, S. (2011). Bayesian model averaging with BMS. R package. https://cran.r-project.org/web/packages/BMS/vignettes/bms.pdf. 